\section{Artigos $-$}

Helena Moreira Schiel (École des Hautes Études en

\section{Sciences Sociales)}

\title{
Os itxoí, ou grupos de praça Karajá. As organizações triádicas existem?'
}

O texto que deu origem ao presente artigo foi escrito há quase dez anos para uma comunicação no III Encontro Macro-Jê. Naquele momento eu pretendia chamar a atenção para a proposta de Nathalie Pétesch de interpretação do universo simbólico karajá em termos da "abertura do dualismo concêntrico em uma tríade", à maneira de Lévi-Strauss, mostrando sua aplicabilidade em um caso específico (Pétesch 1987; Lévi-Strauss 1958b). Com efeito, as ideias de Pétesch haviam encontrado considerável resistência de seus pares, os karajólogos ativos de então. Além disso, o próprio modelo do dualismo já estava um tanto fora das discussões, seja por seus formalismos em excesso, seja por sua aparente pouca dinâmica. A proposta de Pétesch, entretanto, me parecia bastante eficaz na explicação de dados mais rebeldes da etnografia karajá.

Desde então muita coisa mudou. A tardia publicação da versão original do presente texto e seu posterior desenvolvimento em minha dissertação (cf. [Cavalcanti-] Schiel, 2007 e 2005, respectivamente) contribuiu para o reconhecimento da eficácia do modelo triádico por parte dos karajólogos. Os trabalhos mais recentes não se furtam a lidar com o universo simbólico karajá em termos de triadismo, ou ternarismo (Rodrigues 2008; Nunes 2009, 2012) - ao contrário, utilizam-no largamente. Um trabalho independente também confirma a reprodução do modelo triádico em um domínio bastante inusitado, o da distribuição musical (Brígido 2011).

Não apenas o modelo triádico ressurgiu nas análises sobre os Karajá, mas a etnologia das Terras Baixas da América do Sul de modo geral apresenta um crescente reavivamento de discussões em torno dos dualismos Jê, Tupi ou Pano, por exemplo, que levam em conta uma dinâmica e uma assimetria que remetem diretamente ao "perpétuo desequilíbrio" proposto por Lévi-Strauss em A História de Lince (1993)².

O presente artigo é uma versão ampliada da argumentação desenvolvida no capítulo 4 de minha dissertação de mestrado, referente à vida ritual. Incorporar essas novas contribuições sobre os dualismos e assimetrias dos esquemas sóciocosmológicos ameríndios implicaria em uma considerável revisão que não modificaria acentuadamente o que os dados karajá têm a contribuir à discussão. Dessa forma, optei por não incluir aqui os novos debates, acreditando, contudo, que o material karajá seguirá servindo de contraponto aos modelos dualistas mais clássicos, uma 
vez que parece corresponder exatamente à imagem formal da abertura do dualismo concêntrico. Vamos a ele.

Os grupos de língua Jê do Brasil Central entraram para o "mapa" da produção antropológica em nível mundial a partir da descoberta, por Curt Nimuendaju, Robert Lowie e Claude Lévi-Strauss, na primeira metade do séc. XX, de organizações ditas dualistas entre eles. Estes grupos pareciam, aos olhos dos primeiros pesquisadores, um tanto paradoxais. Sem dispor da "tecnologia" observada entre seus vizinhos da floresta tropical (tais como redes de dormir, panelas de barro, bebida fermentada, entre outros), os grupos do cerrado centro-brasileiro apresentavam um alto grau de complexidade em sua organização social no que tange a aspectos como organização em metades e intensa atividade ritual. A ocorrência dos dois fenômenos concomitantes, pouca tecnologia e complexa organização social, já haviam servido para o questionamento da noção de primitivismo ou arcaísmo ${ }^{3}$, mostrando que pouco desenvolvimento tecnológico não corresponderia necessariamente a uma organização social mais simples.

O fértil Projeto Harvard-Brasil Central (doravante PHBC) - que, na década de 1960, voltou suas atenções para os grupos Macro-Jêt - foi, em grande parte, inspirado nos modelos de organizações dualistas propostos por Lévi-Strauss em seu clássico artigo: "Les organisations dualistes existent-elles?" (Lévi-Strauss 1958b).

Tardiamente classificados no tronco lingüístico Macro-Jê, os Karajá parecem ter sido inicialmente excluídos daquele boom de produção etnográfica imediatamente posterior ao PHBC. Os dados karajá dificilmente despontavam como alvo de debates mais amplos na disciplina e, por algum tempo, os karajá permaneceram como um elemento curiosamente anômalo. Acredito que aquela aparente anomalia devia-se, entre outros motivos, a essa tardia classificação lingüística bem como à dificuldade de se encaixar a organização social karajá nos clássicos esquemas de estruturas dualistas Jê-Bororo.

O título do presente artigo é, naturalmente, uma referência àquele clássico artigo de Lévi-Strauss, inspirador do PHBC. A parte usualmente menos explorada daquele texto seminal revelou-se como a de maior rendimento analítico para o caso karajá. Tratava-se, ali, de analisar dados sobre as alianças matrimoniais bororo (Brasil Central) fornecidos pelos padres Colbachini \& Albisetti (1942), comparados aos dados winnebago (América do Norte), oferecidos pela etnografia de Paul Radin (1923). Lévi-Strauss propõe, já ali, uma dinâmica entre o que ele chama de dualismo diametral e dualismo concêntrico.

Por dualismo diametral entende-se uma forma de representação que engloba o cosmos numa totalidade fechada. Essa representação lança mão de classificações que dispõem em pares antitéticos os seus termos, tais como sol e lua, preto e branco, esquerdo e direito, nascente e poente, entre outros, que podem ser tanto simétricos quanto assimétricos. Para Lévi-Strauss, “Num sistema diametral (...) o terreno virgem [circundante à aldeia, p. ex.] representa um elemento não pertinente; as metades se definem uma em oposição à outra e a aparente simetria de sua estrutura cria a ilusão de um sistema fechado" (Lévi-Strauss 1958b: 168).

Já o dualismo concêntrico seria aquele no qual há uma oposição de termos que devem ser necessariamente desiguais. A desigualdade dos termos é intrínseca à estrutura concêntrica, visto que os elementos que se opõem seriam ordenados em relação a um mesmo termo de referência, o que, numa representação gráfica, tomaria o aspecto de um centro. Essas classificações, no nível sociológico, poderiam ou não estar associadas a prescrições matrimoniais.

Aquilo que parecia, à primeira vista, manifestação de uma exogamia de metades entre os Bororo, foi sugerida 
por Lévi-Strauss como, na verdade, uma endogamia de grupos tripartidos no interior da aldeia. Dessa forma, ele propõe que o dualismo concêntrico seria um mediador entre o dualismo diametral e o triadismo:

“Estas diversas manifestações de dualismo dão lugar a uma estrutura triádica: com efeito, cada um dos 8 clãs é dividido em 3 classes que eu chamarei: superior, mediana, inferior (...) a regra segundo a qual um superior de uma metade desposa obrigatoriamente um superior de outra, um mediano um mediano e um inferior um inferior, converte a sociedade bororo de um sistema de aparente exogamia dualista num sistema real de endogamia triádica" (Lévi-Strauss 1958b: 159).

Questionando-se sobre as relações entre as três formas de representação, Lévi-Strauss concebe que o dualismo e o triadismo seriam indissociáveis e conclui que "o dualismo concêntrico é ele mesmo um mediador entre o dualismo diametral e o triadismo e é por intermédio dele que se faz a passagem de um para outro" (idem: 167).

Como corolário de suas explanações, Lévi-Strauss sugere, como representação gráfica, a abertura dos círculos concêntricos duais em uma reta: "se é possível estender o círculo periférico sobre uma reta (...) o centro será exterior a esta reta, sob a forma de um ponto. No lugar de dois segmentos de reta teremos então uma reta e um ponto" (idem: 168). O autor conclui, assim,

“Veremos que as antíteses que servem para expressar o dualismo surgem de duas diferentes categorias: umas verdadeiramente, outras falsamente simétricas. Estas últimas não são mais do que tríades, disfarçadas de díades graças ao subterfúgio lógico que consiste em tratar como dois eixos homólogos um conjunto formado, na verdade, de um pólo e um eixo, que não são objeto da mesma natureza." (ibidem: 170).

A pertinência em se tratar a organização social karajá nos termos de uma estrutura triádica foi notada primeiramente pelo etnólogo suíço Hans Dietschy. Fazendo referência ao artigo de Lévi-Strauss, Dietschy registra entre os Karajá a existência de três grupos rituais que seriam endógamos e patrilineares. O autor explora a composição destes grupos, os itxoi ${ }^{5}$, circunscrevendo-o no espaço da aldeia (Dietschy 1977). Para o autor,

\footnotetext{
“Não existem metades patrilineares propriamente ditas (muito menos matrilineares ou clãs), mas três grupos patrilineares. Os Karajá foram e são principalmente tricáicos como os antigos dórios. Mas os 'verdadeiros moradores' (...) [referindo-se a um grupo do meio, os Mahãdu. Voltarei a este ponto], se opõem, com seus privilégios, aos outros dois grupos, tanto quanto estes, divididos entre 'gente do rio acima' e 'gente de rio abaixo' competem entre si" (Dietschy 1977: 78).
}

O fenômeno desta divisão triádica foi também registrado por Fénelon Costa (1979), apoiando-se em seu principal informante, Arutana. Nathalie Pétesch veio a aprofundar mais minuciosamente a proposta e o modelo de uma estrutura triádica para os karajá (Pétesch 1987, 1993). Pretendo aqui esboçar a argumentação desta autora para, a partir do modelo proposto por ela, proceder à análise de um fenômeno etnográfico que tomo como caso exemplar de estudo: o caso dos itxoí, ou grupos de praça.

A narrativa cosmogônica karajá estabelece, no que Pétesch chama de edifício cósmico, um princípio triádico fundamental (Pétesch 1993: 371). Nele encontramos o nível de baixo, ou Mundo das Águas, de onde teriam vindo os ancestrais dos Karajá. Esse nível seria caracterizado pela imobilidade, pela umidade, pela fartura e pela imortalidade. Dali teriam ascendido os primeiros humanos para o Mundo Terrestre, ou nível do meio. Este, onde vivem os humanos atuais, é caracterizado pela ampla mobilidade, pela presença e necessária relação com a afinidade 
e a morte e por seu ambiente ser mais seco. Após a convivência com os heróis culturais neste nível do meio e a partir de erros cometidos pelos humanos, aqueles heróis ascendem ao terceiro nível, ou Mundo das Chuvas, para onde também se encaminham poderosos xamãs após a morte. Este terceiro nível guarda forte semelhança com o primeiro pela presença de umidade, imortalidade e fartura.

Para Pétesch, haveria uma oposição assimétrica entre, de um lado, a posição mediana e, de outro, as posições extremas, associadas e assemelhadas. A oposição em três elementos não poderia ser reduzida em uma representação simplesmente dualista, uma vez que os dois níveis extremos só existiriam em função da mediação exercida pelo terceiro elemento. O caráter ternário do sistema seria, portanto, predominante (Pétesch 1987: 81).

A composição dos patamares cosmológicos mostrou-se reveladora de um princípio triádico de classificações tornando-se uma referência para a abordagem do triadismo em outros níveis de interpretação. Com efeito, a reprodução desse modelo triádico tanto na concepção cosmológica quanto no arranjo sociológico me parece sugerir a necessidade de romper certas distâncias - analíticas - entre cosmologia e organização social abordando o fenômeno do ponto de vista geral das "formas de classificação".

A ampliação do alcance interpretativo do triadismo (ou ternarismo) para outros domínios do universo simbólico tais como a diacronia ou historicidade, como faz Patrícia Rodrigues (2008: 243), vem a reforçar sua eficácia enquanto princípio classificatório. Tal como sugere ironicamente Almeida:

Como se sabe, Lévi-Strauss foi o primeiro, em O Pensamento Selvagem, a mostrar que as classificações primitivas não são simplesmente funcionais como pensaria um durkheimiano. Elas são exageradas até os limites da neurose obsessiva, face às exigências sadias da adaptação biológica. Regras de parentesco e padrões estéticos, mitos e etiqueta apresentam essa mesma tendência delirante (Almeida 1988: 217).

É nesse sentido, de sua reprodução em diversos domínios, que tratarei o triadismo como um sistema classificatório.

Formulados naquilo que denominei arranjos cerimoniais, os princípios classificatórios vão, nas manifestações rituais, tomar um aspecto sociológico, classificando grupos sociais. Os arranjos cerimoniais na forma dos itxoí, grupos de praça, parecem se revelar como particularmente iluminadores das relações entre dualismo e triadismo a partir dos Karajá.

Itxoí, vocábulo que aqui traduzimos como grupos de praça ou grupos cerimoniais, é um termo polissêmico. Ele pode designar a coletividade masculina ou sua circunscrição no espaço da aldeia. Com efeito, a aldeia Karajá é composta por uma ou mais fileiras de casas residenciais ao longo do rio e uma outra casa, afastada das primeiras, em sua altura mediana, voltada para a mata. Esta casa solitária, conhecida como Hetokré ou Casa dos Homens, e o espaço à sua frente são chamados de itxoí, sendo que este espaço entre a casa e os caminhos que ligam as unidades residenciais à Casa dos Homens é chamado de itxoina, ou seja, praça ou lugar dos itxoí.

Aqui já se destaca a semelhança da planta da aldeia Karajá com aquela idealização gráfica, proposta por Lévi-Strauss, de como seria a abertura da estrutura dual concêntrica numa tríade, ou seja, uma reta - a fileira de casas residenciais - e um ponto - a Casa dos Homens, que assumiria a posição de um centro exteriorizado. A conferir na figura: 


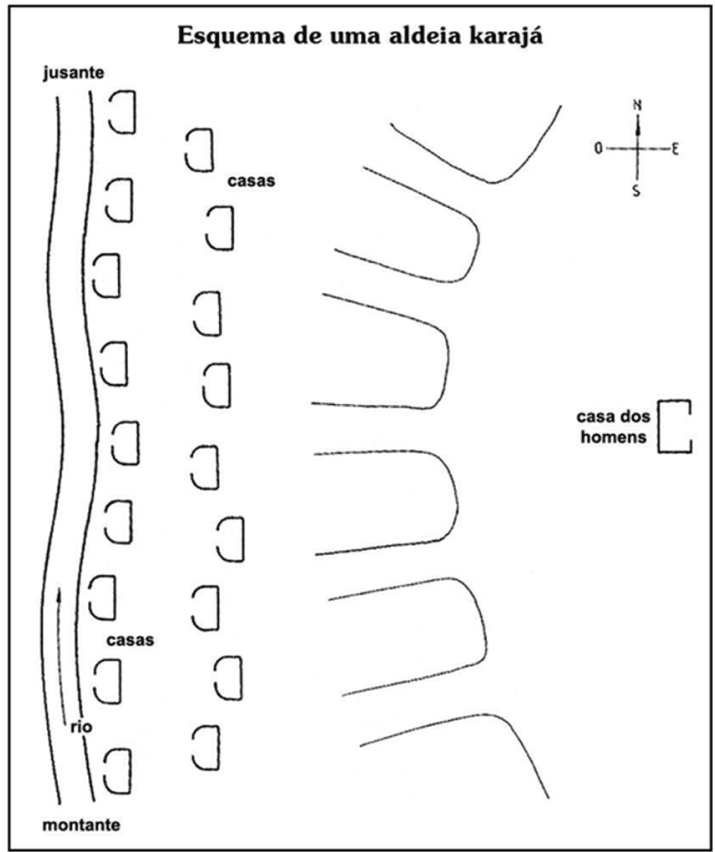

Fonte: Pétesch 2000: 38.

Outro significado do termo itxoi - que nos interessa aqui particularmente - é o de "grupos de praça" (Toral 1992:117) ou "grupos rituais" (Lima Filho 1994:130). Segundo André Toral, a população de uma aldeia se divide entre dois ou mais grupos de praça (itxoí) que cooperaram competitivamente. Ambos autores afirmam que a transmissão do pertencimento ao itxoí se daria patrilinearmente ${ }^{6}$. Ademais, enquanto para as mulheres e crianças o pertencimento ao grupo de praça concerne apenas ao seu posicionamento espacial em determinados rituais, para o homem ele determina grande parte de sua vida social: grupos de tarefas durante rituais, caçadas e nas guerras de outrora (Lima Filho 1994: 130 e Toral 1992:117). Toral chega a afirmar que "Sua [a do homem] situação no seu ijoi particular é o termômetro de seu prestígio social. Líderes de aldeia são ou já foram líderes em seu ijoi" (Toral 1992:117).

Os distintos grupos de praça (itxoí) reagrupam-se sob as designações de ibo(k)ó, montante, e iraru, jusante. George Donahue chama essas duas unidades de metades patrilaterais (Donahue 1982: 280), termo preferido também por Rodrigues, que se refere a eles enquanto metades cerimoniais (Rodrigues, 2008: 561). A referência aos itxoí como "metades" seria pertinente uma vez que os karajá se agrupariam, cotidianamente, sob essas duas denominações abrangentes "grupo de cima", ou montante: ibo(k)ó mahãdu e "grupo de baixo", ou jusante: iraru mahãdu. No entanto, um terceiro grupo, o grupo "do meio', ity(k)a mahãdu, virá perturbar essa dicotomia, sugerindo um arranjo cerimonial não mais em metades, e sim em tércias?. 
O agrupamento dos itxoí em metades ou tércias e sua composição são polêmicas também entre os próprios Karajá. Fénelon Costa alega que Arutana, seu principal informante karajá, contradizia o que afirmavam os outros índios, enxergando classes de homens (segundo a expressão usada por Arutana) divididos, segundo a linha paterna, em três grupos, exatamente da maneira que havia sido descrito por Dietschy. Os outros Karajá afirmavam que homens e mulheres estavam classificados em gente da Casa Grande e gente da Casa Pequena (Fénelon Costa 1978: 39).

Essa discordância entre versões oferecidas pelos nativos, que estão em diferentes relações com a feitura do ritual, evoca a discordância encontrada entre os Winnebago ${ }^{8}$, descritos por Paul Radin e discutidos por Lévi-Strauss. O plano da aldeia, do ponto de vista da gente da metade "de cima", era descrito como a bipartição diametral de uma aldeia redonda. Quando descrito pela gente da metade "de baixo", falava-se de um círculo menor inscrito em outro, maior, havendo uma oposição entre as casas do círculo e a floresta que as envolve, num sistema francamente concêntrico (cf. Lévi-Strauss 1958b: 156).

A discordância, antes de revelar uma insuficiência de dados, parece-me revelar a operacionalidade de uma dinâmica entre lógicas classificatórias que podem não ser mutuamente excludentes. Essas divisões entre tércias e metades se tornam mais visíveis durante as fases mais intensas dos dois ciclos rituais Karajá: o Hetohokã, ou festa da Casa Grande, e o ljasó Anarakã, festa/dança dos ijasó (conhecida em português como dança dos Aruanãs). Cotidianamente, os grupos de praça parecem agrupar-se nas metades "de cima", ibo(k)ó, e "de baixo", iraru. O arranjo em tércias se tornará explícito na última fase do ritual de iniciação masculina (o Hetohokã), para a qual são erguidas, no itxoina (a praça cerimonial), construções que parecem reverberar aquele princípio triádico de classificações. Nesse caso, esse princípio tomará um aspecto sociológico, compondo as tércias anteriormente mencionadas. Uma certa alternância entre arranjos duais e triádicos, antes de nos conduzir a propor uma "solução" entre essas duas alternativas, nos permitiria supor que aqui estaria operando uma dinâmica entre dualismo e triadismo. Iremos propor, de maneira tentativa, uma hipótese para o funcionamento desta dinâmica.

É fundamental observar que os dois ciclos rituais reforçam e animam diferentes relações em uma aldeia. Enquanto a Dança dos ljasó (ljasó Anarakã) tem um caráter intra-comunitário, o Hetohokã implica necessariamente uma relação extra-comunitária. No primeiro, os oficiantes do ritual são da própria aldeia. No Hetohokã a relação com o exterior é fundamental ${ }^{9}$ - seja sob a forma de uma alteridade humana, expressa no convite formal a outra aldeia; seja sob a forma de uma alteridade sobrenatural, os espíritos dos mortos e espíritos de animais, invocados em muitos momentos.

O Hetohokã, que foi interpretado como "ritual de iniciação masculino" (Lima Filho 1994), é um ciclo ritual que tem a duração de aproximadamente um ano agrícola e revela seu ápice no período das chuvas e da cheia do rio Araguaia. É caracterizado pela "visita" (representação) de determinadas entidades cosmológicas que procuram estabelecer a continuidade de suas relações com a comunidade, seja participando e protegendo os garotos que estão sendo iniciados, seja relembrando à comunidade sua moralidade ideal. Para a fase final do ritual é construída uma parafernália que expressa o que estamos chamando aqui de princípio triádico de classificações.

Entre os Karajá propriamente ditos são erguidas duas casas, uma grande, a Hetohokã, e uma pequena, a Hetoriore, que estão respectivamente associadas aos grupos de Cima e Baixo, iboó e iraru. Estas duas casas são ligadas entre si por um corredor (e ele é assim concebido), chamado de Hererawo. A construção deste corredor está diretamente ligada a estes grupos de praça, os itxoí, e aos eventos do Hetohokã. 
Cada um dos esteios que sustentam e compõem este corredor leva o nome de um dos grupos de praça e é, consequentemente, associado a "cima" ou "baixo". Além disso, cada um deles corresponde a um dia da fase final de atividades rituais, funcionando como uma espécie de calendário ritual. Segundo André Toral (1992), a quantidade de esteios que dão sustentação ao corredor varia segundo a quantidade de grupos de praça que existem na aldeia determinada (aldeias maiores comportam maior número de itxoí, grupo de praça). Citando Toral,

“nas maiores aldeias Karajá, Sta. Isabel e Fontoura, nota-se que diversos ijoi [grupos de praça] ocupam os mesmos 'endereços' no Hererawo, associando-se sob as mesmas espécies vegetais [os esteios anteriormente descritos] ou separando-se, sentando-se sob as espécies vegetais vizinhas. Nesse sentido cada ijoi karajá parece poder ser agrupado dentro de uma série de espécies vegetais desde que sejam, como ele, 'de baixo' ou 'do alto'" (Toral 1992:127).

Aparentemente a divisão básica dos itxoí karajá seria cima e baixo em situações cotidianas. O que vai, finalmente, articular a existência de um terceiro grupo são as ocasiões dos rituais. Chega a ser temerário tentar distinguir uma situação cotidiana de um momento ritual, visto que os ciclos rituais karajá se prolongam por um ano ou mais, sendo raras as semanas em que não se representa ao menos uma entidade cosmológica. No entanto, se um Karajá é questionado acerca de a que itxoí ele pertence e de quais seriam os outros, dificilmente ele faria referência imediata a este terceiro, o grupo do meio - como fica bem explícito na menção aos informantes de Fénelon Costa, anteriormente citado. Os comuns reconheciam apenas os grupos da Casa Grande e da Casa Pequena, enquanto o chefe cerimonial reforçava a existência de três grupos:

Todos os informantes, portanto, com exceção de Arutâna, mencionaram a existência de dois e não três grupos cerimoniais. Arutâna explicou que entre a Casa Grande e a Pequena seria construída a Casa do Meio, onde ficaria a gente do meio, Ituámahadô e, de fato, mais tarde foi feito um caminho coberto, ligando as duas casas(Fénelon Costa 1978: 40).

Durante o Hetohokã são organizados grupos para trabalhos específicos, como a construção das casas cerimoniais ou a realização de caçadas ou pescarias concernentes a atividades do próprio ritual. Lima Filho procura demonstrar que os homens de cima, ibo(k)ó mahãdu, constroem a casa grande, que fica à montante do rio, enquanto que os homens de baixo, iraru mahãdu, constroem a casa pequena, que fica a jusante (Lima Filho 1994: 85), sem especificar a qual grupo caberia a construção do Hererawo, o corredor que une as duas casas.

Falando do Hererawo, o corredor, afirma:

“...no espaço de $40 \mathrm{~m}$ entre a Casa Grande e a Casa Pequena é construído um corredor de palha chamado Hererawo. (...) As árvores [é como ele denomina os esteios] decrescem em altura a partir da Casa Grande.(...) A primeira árvore a contar da Casa Grande (...) pertence a um grupo especial de homens denominado Mahãdu Mahãdu. [A] árvore da entrada da casa Grande e as outras duas que ficam após a árvore do Mahãdu Mahãdu pertencem aos homens de cima, os Iboó Mahãdu, e as últimas três mais próximas da casa Pequena são dos Homens de Baixo, os Iraru Mahãdu" (Lima Filho 1994: 85).

O autor observa ainda que os homens que fazem parte do Mahãdu Mahãdu são oriundos tanto do grupo de cima quanto dos de baixo (idem: 99). Sugerimos a seguinte figura como ilustração da distribuição dos grupos pelas casas e pelo corredor. 


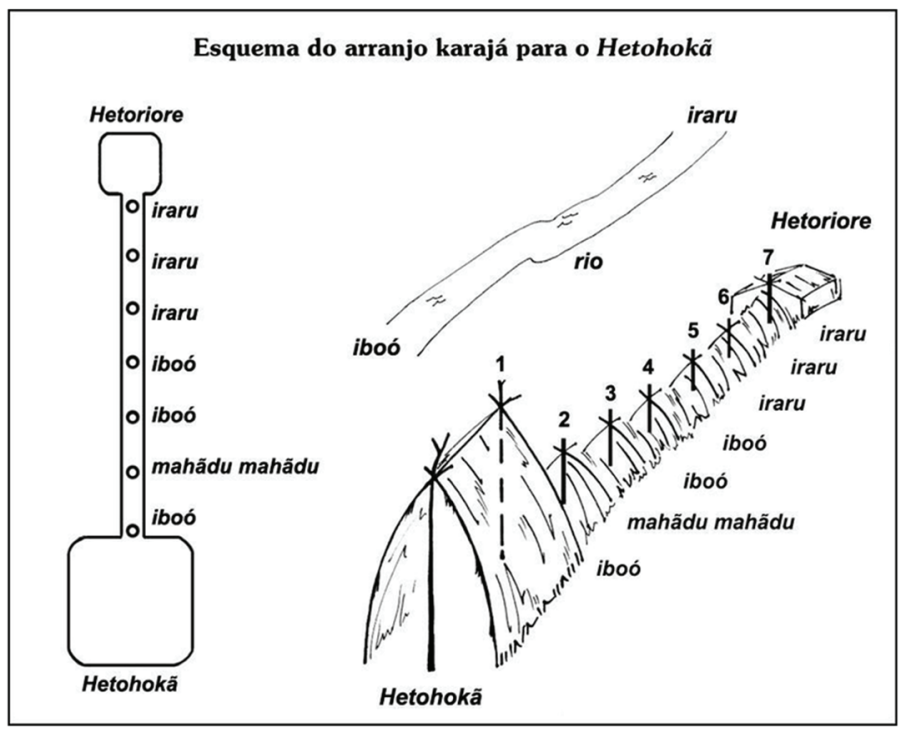

No caso específico javaé, há algumas distinções complementares, mas que não parecem alterar a estrutura fundamental. É importante informar que entre os Javaé existem apenas dois grupos de praça, o Saurá (ou grupo dos macacos) e o Hirètu (grupo da cauda do carcará). Os Javaé mencionam geralmente os nomes desses dois grupos, sem fazer necessariamente referência a ibo(k)ó e iraru (montante e jusante, respectivamente). Toral (1992) menciona ainda um terceiro grupo, os Ity $(k)$ a, traduzido como "grupo do meio" e que só seria visível em funções cerimoniais específicas. Para a ocasião do Hetohokã Javaé, é construída apenas uma única grande casa que reúne os três grupos, sendo que os Ity(k)a, os "do meio" ficam em posição mediana, entre os Saurá, "de cima", que ficam na extremidade sul (ou montante) da casa, e os Hirétu, "de baixo", que ficam na extremidade norte (à jusante). Os troncos que dão a sustentação a essa Casa Grande são de espécies distintas e cada um dos grupos (Saurá ou Hirétu) é dito ser o "dono" de um deles. Além disso, esta casa grande possui três portas, cada uma pertencendo a um grupo. Sobre a composição do grupo intermediário, diz o autor: "Uma pessoa não se liga aos Itya como se liga aos Hirètu e Saurá. Os itya, 'os do meio', são um grupo formado por pessoas de outros ijoi para exercerem funções cerimoniais específicas" (Toral 1992:123).

A seguir propomos outra ilustração que mostra graficamente os esquemas javaé e karajá no Hetohokã, e suas associações com a referência primordial que é a orientação montante/jusante do rio Araguaia. O toó, aqui ilustrado, mas não mencionado no texto, é um tronco de vários metros que é posto no meio da praça ritual (itxoina, lugar do itxoi). Em torno dele é realizada uma disputa entre aldeias, em que os anfitrióes tentam proteger o tronco dos convidados, que tentam derrubá-lo. Segundo descrições de alguns Javaé, no ritual javaé não há o toó e, consequentemente, inexistem as disputas em torno dele. 


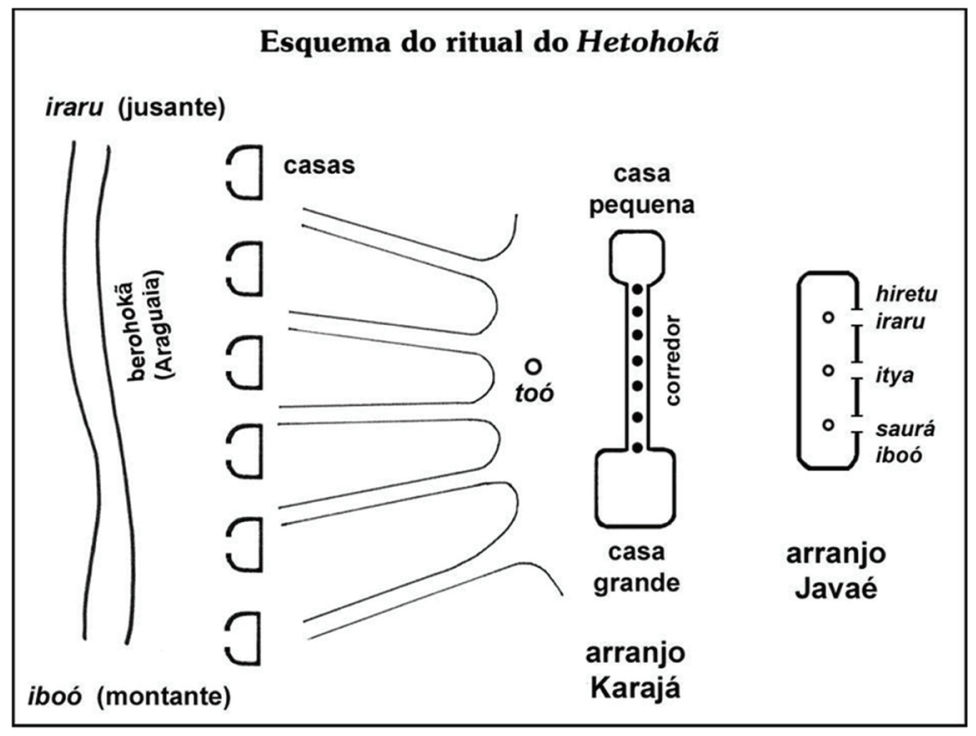

Ainda sobre o Hererawo, o corredor, e agora tratando-se de grupamentos humanos, é no interior desse corredor que se revelam os três grupos rituais, ou itxoí. Lembremo-nos que cada esteio corresponde a um itxoi, com um nome animal e que há apenas um esteio pertencente aos Mahãdu Mahãdu. O grupo do meio — ity(k)a mahãdu, para os Javaé, Mahãdu mahãdu, para os Karajá —, único grupo que compõe a terceira tércia, tem na atualidade, ao que tudo indica, uma composição intermitente. Quem seriam, afinal, os componentes desse terceiro grupo? Pétesch, Lima Filho e Toral concordam que os Mahãdu Mahãdu seriam os membros mais velhos da aldeia. São anciãos, não participam das caçadas e pescarias rituais, mas preparam e distribuem os alimentos oriundos dessas caçadas. Assumem funções unicamente cerimoniais. A comida e a bebida dos Mahãdu Mahãdu são interditas aos outros dois grupos, assim como também é interdito o acesso à fogueira dos Mahãdu Mahãdu (que está sempre acesa junto ao esteio a eles correspondente). Ademais, são eles os responsáveis pela distribuição ritual das partes da caça. Os membros posteriores e a cabeça são dados aos Ibo(k)ó Mahãdu (os de cima), os membros traseiros são dos Iraru Mahãdu (os de baixo) e o meio, a parte mais gordurosa da caça, pertence aos Mahãdu Mahãdu.

Estamos finalmente em condições de propor uma comparação desta parafernália ritual com a partição cosmogônica fundamental. Dispostas verticalmente segundo a orientação do eixo do rio, as construções do Hetohokã karajá dispõem de duas Casas $(H e t o)^{10}$. Elas são unidas entre si por um corredor (Hererawo) que parece fornecer a esta estrutura sua dinâmica propriamente temporal: o corredor opera como um calendário ritual. Além disso, o corredor parece prover a essa estrutura sua característica de marcador (diferenciador) sócio-espacial: os esteios - espaço - são associados aos grupos sociais, os itxoí. Por sua vez, o cosmo karajá é constituído de dois patamares extremos - o mundo das chuvas e o mundo subaquático — que se opõem conceitualmente a um meio 
— o mundo terrestre - que os une e os separa. É no patamar intermediário que o tempo tem lugar. Comparado com os reinos da imortalidade e imobilidade dos patamares extremos, o mundo terrestre é o espaço dinâmico, da passagem do tempo, do movimento, da alteridade, da mortalidade. Curiosamente, a glosa do termo Hererawo como "corredor" revela a coincidência com a idéia de que o patamar intermediário é um local de passagem, onde se dá necessariamente a mobilidade. Nesses termos, acredito ser pertinente associar as Casas Grande e Pequena de um lado e os patamares celeste e subaquático de outro. $O$ terceiro elemento que os conecta seria o corredor (Hererawo), para as construções rituais; e o patamar terrestre, para a geografia cosmológica.

\section{CONCLUSÃO}

Em face da interpretação do arranjo cerimonial enquanto manifestação do princípio classificatório, acredito poder sugerir uma hipótese para explicar o funcionamento da dinâmica entre dualismo e triadismo a partir de uma perspectiva karajá. Os regimes da sociabilidade amazônica se revelaram, na análise de Viveiros de Castro, como estruturalmente constituídos por um dualismo concêntrico, essencialmente assimétrico. Em seu interior encontramos a consanguinidade e, ao afastarmo-nos dele, encontramos uma gradação de formas de afinidade/alteridade, que, por fim, se revela triádica: "A oposição entre consanguinidade e afinidade, direta e indiretamente expressa nas terminologias dravidianas, funciona, então, nos sistemas amazônicos, segundo um regime concêntrico, potencialmente ternário e graduável" (Viveiros de Castro 2002: 134). Entre os Karajá, curiosamente, o inverso parece ocorrer.

No interior do socius encontramos o que venho chamando aqui de triadismo sociológico, em que encontramos efetivamente três grupos de praça, ibo(k)ó, ity(k)a, iraru, cima, meio e baixo, respectivamente. É o caso do ritual dos ljasó, em que apenas os membros da aldeia estão implicados como oficiantes do ritual.

Já se nos afastamos do "centro", em direção à exterioridade, o regime vai se revelando menos matizado e essencialmente dualista. Um exemplo paradigmático desta dinâmica seria a relação inter-aldeias no Hetohokã, em que os homens da aldeia anfitriã, outrora agrupados em seções de cima, meio e baixo, rearranjam-se para denominar a si mesmos de grupo de cima, ibo(k)ó, recebendo com disputas rituais a aldeia visitante, também rearranjada, sob a alcunha de grupo de baixo, iraru11, ou seja, uma oposição binária simples. A assimetria é explicitada no jogo da disputa pelo toó, em que o grupo de cima deve, obrigatoriamente, vencer, impedindo a derrubada do toó, assegurando sua superioridade estatutária.

Reconhecemos que esta proposta ainda pode parecer prematura. No entanto, ela tem se mostrado pertinente para explicar o caso karajá. Acredito que os arranjos cerimoniais karajá possam contribuir para uma compreensão mais ampla das dinâmicas entre dualismo e triadismo. A contribuição maior que o conhecimento dessas dinâmicas pode fornecer seria o refinamento dos modelos teóricos que venham a dar conta daqueles aspectos mais problemáticos do dualismo centro-brasileiro.

Com efeito, suspeito que a lógica triádica seja operante no domínio “interior" do socius. Quando se trata de relações com os diversos tipos de exterior, a alteridade, a lógica classificatória parece assumir um caráter francamente dualista. Esse deslizamento entre lógicas triádicas e duais é particularmente nítido nas atividades rituais. Enquanto a atividade ritual concerne apenas à aldeia, encontramos os homens agrupados em tércias. Quando se trata de visitas e confrontos 
ritualizados inter-aldeias, as tércias desaparecem para dar lugar ao enfrentamento entre as metades "de cima", a aldeia anfitriã, e "de baixo", a aldeia visitante. Acredito que haja ainda muito a ser feito no refinamento dos modelos que deem conta do universo classificatório karajá.

A necessidade de uma reflexão mais detida em torno do problema do triadismo, inscrito no problema maior das relações assimétricas que seriam responsáveis por um perpétuo desequilíbrio, vem sendo sentida por diversos autores. Lévi-Strauss, no último volume de suas Mitológicas, destaca a diferença do pensamento indo-europeu, que insiste na realização de um ideal de gemelaridade perfeita, com o pensamento ameríndio. Neste, "parece indispensável uma espécie de clinâmen filosófico para que em todo e qualquer setor do cosmos ou da sociedade as coisas não permaneçam em seu estado inicial e que, de um dualismo instável em qualquer nível que se o apreenda, sempre resulte um outro dualismo instável" (Lévi-Strauss 1993: 209).

Marcela Coelho de Souza, em revisão exaustiva da produção etnográfica sobre os Jê, destaca as proposições de Lévi-Strauss, lembrando que, ao intitular aquele clássico artigo de "As organizações dualistas existem?", o autor pretendia que a resposta, que passara largamente despercebida da etnografia, seria que não, as organizações dualistas não existem, o que existe é um triadismo subjacente aos aparentes dualismos. Nas palavras da autora: “... a exploração em questão o levará justamente a propor que os diversos dualismos 'sociológicos' (com ou sem metades, e, no primeiro caso, sejam estas exógamas ou não) 'supõem e recobrem' estruturas de aliança não dualistas, isto é, triádicas." (Coelho de Souza 2002, 163).

Viveiros de Castro, lidando com o fenômeno do dravidianato amazônico e com a inclusão do terceiro elemento nas relações de parentesco, que escapa à dualidade do consangüíneo e do afim, sugere que "O ternarismo, inerente ao regime concêntrico da sociabilidade amazônica (...) vai encontrar uma manifestação clara na forma daqueles que eu chamaria de 'terceiros incluídos', posições que escapam ao dualismo consangüíneos/afins e parentes/estrangeiros, e que desempenham funções mediadoras fundamentais" (Viveiros de Castro1993: 177-178).

Espero que o material Karajá tenha se tornado ilustrativo de um caso de triadismo em que este se mostra em relação dinâmica com outros arranjos - esses, dualistas. Neste caso, o ritual revela-se como o momento apropriado da manifestação de princípios classificatórios, como é o caso dos grupos de praça Karajá.

Retornando ao título da comunicação, se Lévi-Strauss, no seu famoso artigo, pretendia pôr em questão a, digamos assim, realidade exaustiva das organizações dualistas, pretendi aqui reiterar o quanto pode ser instigante pensar a propósito das mediações triádicas, tenham elas ou não um "lugar" etnográfico necessário (Karajá) - eu preferiria pensá-los, antes, como "manifestações". Isso implica em vencer as distâncias que separam objetos como por exemplo, "organização social" e "princípios classificatórios".

Helena Moreira Schiel é Mestre em Antropologia Social pela Universidade de São Paulo (USP). Atualmente é doutoranda do Laboratoire d'Anthropologie Sociale da École des Hautes Études en Sciences Sociale (EHESS - França) e 


\section{NOTAS}

1 Quero agradecer a colaboração e sugestões de Marcos Lanna, Jayne Colevatti e Ricardo Cavalcanti-Schiel. A este, também, a colaboração no incluir de figuras explicativas. As imprecisões e eventuais equívocos são de minha inteira responsabilidade.

2 Sem pretensão de exaurir o ressurgimento dessa discussão, cf, por exemplo Peggion 2011, Lagrou 2007 e, sobretudo, Lima 2008.

3 Como em Lévi-Strauss 1958a, "La notion d'Archaïsme en Ethnologie".

4 O Projeto Harvard-Brasil Central torna-se responsável por um verdadeiro boom (ainda em curso) de produções etnográficas de grande qualidade técnica e teórica, bem como uma projeção maior da etnografia e da etnologia das sociedades ameríndias das Terras Baixas no contexto dos debates mais abrangentes da disciplina. Para uma análise orientada do projeto e das etnografias Macro-Jê, cf Coelho de Souza 2002

5 Nos trabalhos anteriores em que me dediquei ao material Karajá, sempre registrei esse termo como "ijoi", que corresponde à sua pronúncia masculina. Com efeito, a língua karajá conhece diferenças de pronúncias masculina e feminina em certas palavras, geralmente um "k" ou " $t x$ " entre duas vogais, para mulheres, onde homens pronunciam apenas o encontro vocálico. Na medida em que fui incrementando minha proficiência na língua, os Karajá passaram a ser exigentes com sua correção. Assim, descobri que este conceito com o qual eu lidava há anos tinha uma versão na pronúncia feminina. Menos por desejo de afirmação de uma identidade de gênero e mais por ter sido lembrada constantemente de que não há uma pronúncia padrão (a masculina) da qual a outra (feminina) é derivada e sim que eu deveria pronunciar dessa forma, passarei a usar o termo itxoí na pronúncia feminina. Nos outros termos em que houver diferença de pronúncia, incluirei um "k" entre parênteses, que corresponde à pronúncia feminina, como em ibo(k)ó (iboó p/ homens, ibokó para mulheres)

6 Patrícia Rodrigues, trabalhando exclusivamente com dados Javaé, observou que entre estes a afiliação ao grupo de praça se daria exclusivamente por linha feminina (cf. Rodrigues 2008).

7 Por analogia ao termo "metade", procurei cunhar um conceito que se substituísse à expressão "uma das três subdivisões". A preferência por tércia (do latim tertia, a terceira hora, ou a terça parte de um todo) em lugar de terça ou terço seria justificada pelo uso demasiado popularizado destes dois últimos termos.

8 Grupo indígena norte-americano de língua sioux (cf. Radin 1923).

9 Em sua tese, Rodrigues sustenta que essa necessária relação com a alteridade encontrada no ritual Karajá (como o convite a outra aldeia) não estaria presente entre os Javaé. Não dispomos, ainda, de uma descrição passo a passo do complexo do Hetohokã entre os Javaé para levar adiante uma interpretação desta afirmativa. Entretanto, se esse for o caso, estaremos diante de uma curiosa dinâmica entre concepções do parcial e do todo, do uno e do múltiplo, com variações entre os dois grupos. Este ponto merece ser explorado por análises vindouras.

10 Estou me limitando aqui à variação karajá da construção ritual por comodidade metodológica. Mais detalhado, o esquema karajá mostra-se mais ilustrativo. Reconheço que a variação javaé tem suas particularidades. Não caberia aqui, no entanto, uma exegese das diferenças entre os subgrupos. Essa exegese poderá ser efetuada quando dispusermos de uma descrição etnográfica do Hetohokã javaé, uma vez que parece operar aí dinâmica entre lógicas unitárias ou do todo que talvez indiquem algo sobre a dinâmica dessa variação. De toda forma, como as diferenças entre os esquemas Karajá e Javaé parecem ocorrer sistematicamente, é preciso olhar para elas como variações - sistemáticas - sobre um mesmo tema.

11 Os detalhes do ritual são bem mais complexos do que esse esquema, naturalmente, e além dessa oposição entre anfitriões e visitantes, há a presença ou ocultação de consanguíneos e afins em determinados jogos, solteiros e casados, uma infinidade de pequenas lógicas binárias em que alguns Nós e alguns Outros se enredam. 


\section{REFERENCIAS BIBLIOGRAFICAS}

ALMEIDA, Mauro. 1988. “Dilemas da razão Prática: Simbolismo, tecnologia e Ecologia na Floresta Amazônica”. Anuário Antropológico 86: 213-226.

BRÍGIDO, Suely. 2011. Imagens Encantadas. Arte Ritual. Indios Karajá. Niterói: Ed. Fábrica de Livros/Senai

COELHO DE SOUZA, Marcela. 2002. O traço e o círculo: o conceito de parentesco Jê e seus antropólogos. Tese de Doutorado. Rio de Janeiro: Museu Nacional/ UFRJ

COLBACHINI, P. Antonio. \& ALBISETTI, P. Cesar. 1942. Os Bororos Orientais. São Paulo: Cia Editora Nacional.

DIETSCHY, Hans. 1960. "Note à propos des Danses des Carajá; 'Pas de deux 'Amitié formelle et Prohibition de I'Inceste”. Bulletin de la Société Suisse des Américanistes 19: 1-5.

. 1974. “L'Homme honteux et la Femme-crampon, En marge des 'Mytologiques' de Cl. Lévi-Strauss”. Bulletin de la Société Suisse des Américanistes 38: 35-40.

1977. "Espace Social et 'Affiliation par Sexe' au Brésil Central (Karajá, Tapirapé, Apinayé, Mundurucu)". Actes du LVIIe Congrès Internationale des Américanistes vol. II: 297-308. Paris: Societé des Américanistes.

DONAHUE, George R. 1982. A contribution to the ethnography of the Karajá Indians of Central Brasil. Tese de Doutorado, University of Virginia, Fairfax:Virginia

FÉNELON COSTA, Maria Heloísa. 1979. A arte e o artista na sociedade karajá. Brasília: FUNAI

LAGROU, Els. 2007. A Fluidez da Forma. Arte, Alteridade e agência em uma sociedade amazônica (Kaxinawa, Acre). Rio de Janeiro: Topbooks.

LÉVI-STRAUSS, Claude. 1958a. “La Notion d'Archaïsme en Ethnologie”. Anthropologie Structurale I. Paris: Plon. 1958b "Les organisations dualistes existent-elles?". Antropologie Structurale. I. Paris: Plon. 1993. História de Lince. São Paulo: Cia das Letras

LIMA, Tânia Stolze. 2008. “Uma história do dois, do uno e do terceiro”. In: R. C Queiroz \& R. Nobre (orgs.). Lévi-Strauss. Leituras Brasileiras. Belo Horizonte: Ed. UFMG

LIMA FILHO, Manuel F. 1994. Hetohokÿ, um rito Karajá. Goiânia: Editora da UCG

LOWIE, Robert. 1941. "A note on the northern Gê tribes of Brazil". American Anthropologist XLIII: 188-196. 1943. "A note on the northern Kayapó". American Anthropologist XLV: 633-635.

NIMUENDAJU, C. 1939. The Apinayé. Washington: Catholic University of America Press. 1942. The Serente. Los Angeles: Frederick Webb Hodge Anniversary Publication Fund. 1946. The Eastern Timbira. Berkeley e Los Angeles: University of California Press.

2000. Cartas do Sertão. De Kurt Nimendaju para Carlos Estevão de Oliveira. Apresentação e notas de Thekla Hartmann. Lisboa; Museu Nacional de Etnologia/Assírio e Alvim.

NUNES, Eduardo S. 2009. A Cruz e o ltxe(k)ó: Mestiçagem, Mistura e Relação entre os karajá de Buridina (Aruanã - GO). 
2012. No Asfalto não se pesca. Parentesco, mistura e transformação entre os Karajá de Buridina (Aruanã - GO). Dissertação de mestrado. Brasília: Universidade de Brasília.

PÉTESCH, Nathalie. 1987. “Divinités Statiques, hommes en mouvement. Structure et dynamique cosmique et sociale chez les indien Karajá du Brésil Central". In Journal de la Societé des Americanistes. LXXIII: 75-92.

. 1993. "A trilogia Karajá: sua posição intermediária no continuum Jê-Tupi”. In: E. Viveiros de Castro \& M. Carneiro da Cunha Amazônia: Etnologia e História Indígena. São Paulo: NHII/USP, FAPESP.

2000. La pirogue de sable. Pérénité cosmique et mutation sociale chez les Karajá du Brésil central. Paris: Peeters

PEGGION, Edmundo Antonio. 2011. Relações em perpétuo Desequilíbrio. A Organização Dualista Kagwahiva da Amazônia. São Paulo: Annablume.

RADIN, Paul. 1923. The Winnebago Tribe, 37th Annual Report, Bureau of American Ethnology (1915-16). Washington.

RODRIGUES, Patrícia. 1993. O Povo do Meio. Tempo, Cosmo e Gênero entre os Javaé da Ilha do Bananal. Dissertação de Mestrado: Universidade de Brasília Chicago.

2008. A Caminhada de Tynyxiwé: uma teoria Javaé da História. Tese de Doutorado. Illinois: Universidade de

[Cavalcanti-]SCHIEL, Helena. 2005. O Vermelho, o Negro e o Branco. Modos de classificação entre os Karajá do Brasil Central. Dissertação de Mestrado: Universidade de São Paulo

2007. "As Organizações Triádicas Existem? O caso dos ijoi Karajá". In: A. Rodrigues \& A.S. Cabral (orgs.). Línguas e Culturas Macro-Jê. Brasília: Finatec/Editora UnB.

STEWARD, Julian. (org). 1946-1959. Handbook of South American Indians (7 vols.). Washington: Smithsonian Institution. TORAL, André A. 1992. Cosmologia e Sociedade Karajá. Dissertação de Mestrado. Rio de Janeiro: Museu Nacional - UFRJ VIVEIROS DE CASTRO, Eduardo. 1993. "Alguns aspectos da afinidade no dravidianato amazônico". In: E. Viveiros de Castro \& M. Carneiro da Cunha (orgs.). Amazônia: Etnologia e História Indígena. São Paulo: NHII/USP, FAPESP. 2002. “O problema da afinidade na Amazônia". In: A Inconstância da alma Selvagem. São Paulo: Cosac \& Naify. 


\section{Os itxoí, ou grupos de praça Karajá. As Organizações Triádicas Existem?}

\section{RESUMO}

A parte usualmente menos utilizada do clássico artigo de Lévi-Strauss sobre as organizações dualistas revelou-se como a mais adequada para explicar o universo simbólico karajá. Neste artigo, exploro a formulação do modelo triádico num caso particular, o dos grupos de praça karajá. A partir dele, sugiro uma certa dinâmica entre lógicas duais e triádicas que podem vir a ser exploradas por novas pesquisas.

PALAVRAS-CHAVE: Índios Karajá; Povos Jê; organizações dualistas.

The itxoí or Karajá plaza groups. Do triadic organizations exist?

\section{ABSTRACT}

The section of Lévi-Strauss' classical article on dualist organizations that is seldom explored revealed itself as the most adequate to explain the symbolic universe of the Karajá. In this article, I explore the formulation of the triadic model in a particular case of karajá grupos de praça (plaza groups). From this perspective, I suggest a certain dynamics of dual and triadic logics, which may be explored in further research.

KEY WORDS: Karajá Indians; Ge Speaking Indians; dualist organizations. 